\title{
Effects of microbial inoculants on corn silage fermentation, microbial contents, aerobic stability, and milk production under field conditions
}

\author{
N. B. Kristensen, ${ }^{1}{ }^{1}$ K. H. Sloth,† O. Højberg, ${ }^{*}$ N. H. Spliid,† C. Jensen, $\S$ and R. Thøgersen§ \\ *Department of Animal Health and Bioscience, Faculty of Agricultural Sciences, Aarhus University, DK-8830 Tjele, Denmark \\ †Agro Tech A/S, DK-8200 Aarhus N, Denmark \\ łDepartment of Integrated Pest Management, Faculty of Agricultural Sciences, Aarhus University, DK-4200 Slagelse, Denmark \\ §Danish Agricultural Advisory Service, DK-8200 Aarhus N, Denmark
}

\begin{abstract}
The present study aimed to investigate the effects of 2 corn silage inoculation strategies (homofermentative vs. heterofermentative inoculation) under field conditions and to monitor responses in silage variables over the feeding season from January to August. Thirtynine commercial dairy farms participated in the study. Farms were randomly assigned to 1 of 3 treatments: control (nonactive carrier; Chr. Hansen A/S, Hørsholm, Denmark), Lactisil (inoculation with $1 \times 10^{5}$ Lactobacillus pentosus and $2.5 \times 10^{4}$ Pediococcus pentosaceus per gram of fresh matter; Chr. Hansen A/S), and Lalsil Fresh (inoculation with $3 \times 10^{5}$ Lactobacillus buchneri NCIMB 40788 per gram of fresh matter; Lallemand Animal Nutrition, Blagnac, France). Inoculation with Lactisil had no effects on fermentation variables and aerobic stability. On the contrary, inoculation with Lalsil Fresh doubled the aerobic stability: 37, 38, and $80 \pm$ $8 \mathrm{~h}$ for control, Lactisil, and Lalsil Fresh, respectively. The effect of Lalsil Fresh on aerobic stability tended to differ between sampling times, indicating a reduced difference between treatments in samples collected in April. Lalsil Fresh inoculation increased silage $\mathrm{pH}$ and contents of acetic acid, propionic acid, propanol, propyl acetate, 2-butanol, propylene glycol, ammonia, and free AA. The contents and ratios of DL-lactic acid, L-lactic acid relative to DL-lactic acid, free glucose, and DLlactic acid relative to acetic acid decreased with Lalsil Fresh inoculation. Lalsil Fresh inoculation increased the silage counts of total lactic acid bacteria and reduced yeast counts. The Fusarium toxins deoxynivalenol, nivalenol, and zearalenone were detected in all silages at all collections, but the contents were not affected by ensiling time or by inoculation treatment. The effect of inoculation treatments on milk production was assessed by collecting test-day results from the involved farms and comparing the actual milk production with
\end{abstract}

Received February 4, 2010.

Accepted April 26, 2010.

${ }^{1}$ Corresponding author: nbk@agrsci.dk predicted milk production within farm based on testday results from 2007 and 2008. The average milk production of lactating cows at test days during the study (January to September 2009) was $30.7 \pm 0.5 \mathrm{~kg}$ of energy-corrected milk/d. Milk production was 104.6 $\pm 0.7 \%$ of the predicted yield and did not differ among treatments. In conclusion, the present study showed that homofermentative inoculants might not compete efficiently or might not deviate sufficiently from the epiphytic flora on whole-crop corn to affect fermentation in standard qualities of corn silage. Heterofermentative inoculation increased aerobic stability and numerous fermentation variables. None of the treatments affected milk production, and more-stable corn silage seemed to have a similar production value as compared with less-stable homofermented silage. Heterofermented silage can be evaluated for its properties to limit aerobic silage deterioration in the feed chain.

Key words: Lactobacillus buchneri, Lactobacillus pentosus, silage additive, silage fermentation

\section{INTRODUCTION}

Whole-crop corn is a major crop in many dairy production systems and a crop that is easily fermented to silage, resulting in a valuable feedstuff for dairy cattle that is stable for a long period of time (Weinberg and Muck, 1996). The importance of corn silage to the dairy industry implies that spoilage of corn silage and any undesired microbial activity in corn silage can affect the individual herd as well as have fundamental implications for overall profitability of the industry. The use of microbial silage inoculants to improve silage fermentation and stability has a long history (McDonald et al., 1991), and 2 major microbial silage inoculation strategies are used for corn silage: 1) homofermentative inoculants often based on Lactobacillus plantarum and 2) heterofermentative inoculants based on Lactobacillus buchneri.

Homofermentative inoculants attempt to increase the rate of $\mathrm{pH}$ reduction in the early fermentative phase of ensiling, which might preserve plant protein from deg- 
radation (Muck, 1988) and increase silage palatability due to competitive reduction of acetic acid production (Muck, 1993). However, in general, data on cow performance with homofermentative microbial inoculants in corn silage lack repetitions and lack agreement between studies with respect to cow performance efficacy (Wohlt, 1989; Kung et al., 1993). Furthermore, and of concern to users, homofermentative inoculants might decrease aerobic stability of corn silage (Kleinschmit et al., 2005).

Heterofermentative inoculants have been more recently introduced, and although their efficacy seems promising in laboratory-scale studies (Kleinschmit and Kung, 2006), a recent observational field study indicated that the effect of $L$. buchneri inoculation under field conditions was less than expected from laboratoryscale studies (Mari et al., 2009). Heterofermented corn silages violate traditional quality measures, e.g., they have a markedly reduced lactic acid to acetic acid ratio. However, the available data for whole-crop grain silages do not indicate negative effects of heterofermented silages on cow performance (Taylor et al., 2002).

The objective of the present study was to compare a homofermentative and a heterofermentative microbial inoculation strategy in corn silage with an untreated control by an interventional field study at commercial dairy farms and to evaluate the effects of treatments on silage fermentation, aerobic stability, and microbial contents. In addition, it was our objective to test whether the inoculation strategy affected milk production.

\section{MATERIALS AND METHODS}

\section{Experimental Design, Treatments, and Sampling}

Thirty-nine Danish dairy farms and 7 contractors participated in the study. Contractors were included in the study as blocks, and 3 to 9 dairy farmers volunteered within contractor to participate. Within contractor, dairy farms (experimental unit) were randomly allocated to 1 of 3 treatments, and the entire harvest of whole-crop corn silage at each farm received the same inoculation treatment. Treatments were as follows: control (application of nonactive carrier; Chr. Hansen A/S, Hørsholm, Denmark); Lactisil [inoculation with $1 \times 10^{5}$ Lactobacillus pentosus and $2.5 \times 10^{4}$ Pediococcus pentosaceus per gram of fresh matter $(\mathbf{F M})$; Chr. Hansen A/S]; Lalsil Fresh (inoculation with $3 \times 10^{5}$ L. buchneri NCIMB 40788 per gram of FM; Lallemand Animal Nutrition, Blagnac, France). Corn was harvested with selfpropelled forage harvesters (11 out of 12 harvesters were Claas Jaguar 800 and 900 series, Claas KGaA mBH, Harsewinkel, Germany). Water mixtures of inoculants were injected directly into the discharge accelerator of all harvesters. Corn was harvested from September 8 to November 4, 2008. The study was conducted as a blind study for all who participated in conducting the field experiments, i.e., contractors, farmers, and technicians sampling silages and making field observations.

Farms were visited during ensiling; 3 to 5 whole corn plants were harvested (24 farms) in the field and chopped FM samples from at least 2 wagons were collected in the bunker (all farms). The FM samples were bagged and kept cool during transport to the laboratory. Whole corn plants were bagged and not cooled during transport. Whole plants were processed through a Georg Hansen 33L cutter (Wiencken Maskiner A/S, Copenhagen, Denmark) with a cutting length of 10 to $20 \mathrm{~mm}$. All FM samples were stored overnight at $5^{\circ} \mathrm{C}$ before microbiological plating.

All farms were visited 3 times during the subsequent feeding season: January (wk 4), April (wk 17), and August (wk 35) 2009. At each visit, corn silage samples were obtained by drilling vertical cores $1 \mathrm{~m}$ behind the bunker face in full depth (maximum of $5 \mathrm{~m}$ ), allowing for a safety distance to the floor of about $25 \mathrm{~cm}$. This procedure reduced the likelihood of obtaining samples of silage already spoiled due to imperfect face management but at the same time made it possible to obtain samples representing silage likely to be offered to dairy cows close to the time of sampling. Depending on the bunker height, 1 to 3 cores were collected to obtain sufficient sample material $(2,500 \mathrm{~g})$. The drill was a stainless steel tube (50-mm i.d.) with 4 extension tubes (total length of $5 \mathrm{~m}$ ), a 39 -mm cutting edge, and an electric drive (Frøsalget a.m.b.a., Brørup, Denmark). The drill tube was emptied for every $1 \mathrm{~m}$ of silage. Silage samples were thoroughly mixed, double bagged, kept cool (protected from freezing elements by towels), and brought to the university at the end of the working day. Silage height and silage temperature $100 \mathrm{~cm}$ behind the center of the silage face were recorded (Thermistor thermometer, EcoScan Temp 5 with 1-m temperature probe, Buch \& Holm A/S, Herlev, Denmark).

\section{Chemical Analyses on Fermentation Variables}

Water extracts of silage samples were prepared immediately after arrival at the university by weighing 250 $\mathrm{g}$ of silage and $1,000 \mathrm{~g}$ of deionized water into a blender and homogenizing for $2 \times 30 \mathrm{~s}$ (Waring 24CB10; Waring Commercial, New Hartford, CT). The homogenate was kept cool on crushed ice until centrifugation $(2,300$ $\times g$ at $4^{\circ} \mathrm{C}$ for $\left.20 \mathrm{~min}\right)$. The $\mathrm{pH}$ of the supernatant was measured after centrifugation using a combination electrode (PHC2002-8; Hach Lange APS, Brønshøj, Denmark) and a pH meter calibrated at $\mathrm{pH} 4.005$ and 7.000 (PHM 240; Hach Lange APS). Water extracts 
were stored at $-20^{\circ} \mathrm{C}$ with and without stabilization with 5\% meta-phosphoric acid (final concentration).

Silage extracts stabilized with meta-phosphoric acid were analyzed for free glucose and L-lactate using Dglucose oxidase and L-lactate oxidase, respectively (YSI 7100; YSI Inc., Yellow Springs, OH), VFA by gas chromatography as described previously (Kristensen et al., 1996), and ammonia in samples diluted 1:20 with phosphate buffer using an enzymatic assay (AM 1015; Randox Laboratories Ltd., Crumlin, UK) adapted for use on a Cobas Mira autoanalyzer (Triolab A/S, Brøndby, Denmark). Concentrations of ethanol, propanol, propyl acetate, and 2-butanol in extracts were determined as described previously (Kristensen et al., 2007) except that $\left[2-{ }^{13} \mathrm{C}\right]$ ethanol $(99 \%$, Cambridge Isotope Laboratories Inc., Andover, MA), $\left[1-{ }^{13} \mathrm{C}\right]$ propanol (99\%, Cambridge Isotope Laboratories Inc.), and $\left[1,2-{ }^{13} \mathrm{C}\right]$ ethyl acetate (99\%, Cambridge Isotope Laboratories Inc.) were added as internal standards for ethanol, propanol, and propyl acetate, respectively.

Unstabilized silage extracts were analyzed for alanine, glycine, leucine, isoleucine, proline, valine, benzoic acid, and DL-lactic acid by gas chromatography-mass spectrometry following ethyl chloroformate derivatization (Kristensen et al., 2000). This method was modified by adding [carboxyl $-{ }^{13} \mathrm{C}$ ] benzoic acid $(99 \%$, Cambridge Isotope Laboratories Inc.) and $\left[1,2,3{ }^{13} \mathrm{C}\right]$ lactic acid (98\%, Cambridge Isotope Laboratories Inc.) as internal standards for benzoic acid and lactic acid, respectively. Norvaline was included as internal standard for AA. Samples were analyzed by gas chromatography-mass spectrometry (DSQ, Thermo, Austin, TX) using a VF-1701ms column (30 m, 0.25-mm i.d., 0.25- $\mu \mathrm{m}$ film; Analytical Instruments A/S, Værløse, Denmark).

Propylene glycol content was determined in unstabilized extracts following methanol-chloroform extraction (Bligh and Dyer, 1959). The chloroform extract was analyzed by gas chromatography-mass spectrometry mounted with a polyethylene glycol column (Restek Stabilwax, 30 m, 0.25-mm i.d., 0.25- $\mathrm{mm}$ film; Analytical Instruments A/S) using 1,2-butanediol as internal standard. Calibration of the method resulted in a negative intercept that invalidated determination of low concentrations of propylene glycol in samples. Therefore, all samples, standards, and blanks were spiked with propylene glycol equivalent to a sample concentration of $2 \mathrm{mM}$.

\section{Aerobic Stability}

Measurements of aerobic stability were initiated 1 to $2 \mathrm{~h}$ after arrival of samples at the university. Samples were aerated by thoroughly mixing samples in a plastic bag. A 3-L plastic bucket was filled halfway full with loosely packed silage, and a thermocouple (MLT 1401; ADInstruments, Chalgrove, UK) was placed in the center. The bucket was topped up with loosely packed silage, and a lid was mounted. Temperature data were recorded continuously from each bucket as well as from empty buckets (ambient temperature) using 3 data logger PC setups (one PowerLab 8/30 and 2 PowerLab 16/30, Pod Expanders ML305, T-type pods ML312, Chart 5 version 5.5.4, ADInstruments) and subsequently averaged for 1-h intervals. Stability was defined as the time $(\mathrm{h})$ for the silage temperature to exceed $+2.5^{\circ} \mathrm{C}$ compared with ambient temperature. The silage buckets were held in a temperature-controlled room (19.0 $\pm 0.5^{\circ} \mathrm{C}$ ). Incubation was limited to $240 \mathrm{~h}$, and silages not exceeding $+2.5^{\circ} \mathrm{C}$ above ambient temperature when incubation was terminated were set to being stable for $240 \mathrm{~h}$.

\section{Microbial Counts}

Silage samples (10 g wet weight) were transferred to flasks containing $90 \mathrm{~mL}$ of peptone water containing 10 g/L of Bacto peptone (Merck, Darmstadt, Germany) and $1 \mathrm{~mL} / \mathrm{L}$ of Tween 80 (Merck). The suspension was transferred to a plastic bag and homogenized in a stomacher blender (Interscience, St. Nom, France) for 2 min. Ten-fold dilutions were prepared in peptone water by the technique of Miller and Wolin (1974), and samples $(0.1 \mathrm{~mL})$ were plated on selective media. Lactic acid bacteria (LAB) were enumerated on de Man, Rogosa, and Sharpe agar (Merck) after anaerobic incubation at $37 \pm 1^{\circ} \mathrm{C}$ for $2 \mathrm{~d}$. Coliforms (Enterobacteriaceae) were enumerated on McConkey agar (Merck) after aerobic incubation at $37 \pm 1^{\circ} \mathrm{C}$ for $1 \mathrm{~d}$. Yeasts and molds were enumerated on malt chloramphenicol agar $[10 \mathrm{~g} / \mathrm{L}$ of glucose (Merck), $3 \mathrm{~g} / \mathrm{L}$ of malt extract (Merck), 3 $\mathrm{g} / \mathrm{L}$ of yeast extract (Merck), $5 \mathrm{~g} / \mathrm{L}$ of Bacto peptone (Merck), $50 \mathrm{mg} / \mathrm{L}$ of chloramphenicol (Sigma-Aldrich Chemie GmbH, Steinheim, Germany), and $15 \mathrm{~g} / \mathrm{L}$ of agar (Merck)] following aerobic incubation at $37 \pm 1^{\circ} \mathrm{C}$ for $2 \mathrm{~d}$.

\section{Fusarium Toxins}

Silages were assayed for deoxynivalenol, nivalenol, zearalenone, HT-2, T-2, and fumonisins (FB1 and FB2). Freeze-dried samples of silage $(10 \mathrm{~g})$ were extracted with water:acetonitrile $(16: 84, \mathrm{vol} / \mathrm{vol})$ and analyzed by liquid chromatography-tandem mass spectrometry following a cleanup step using MultiSep 224 columns (Romer Labs, Tulln, Austria) as described previously (Nicolaisen et al., 2009). 


\section{Nutrient Composition of Silages}

Silage contents of starch and CP and in vitro digestibility were determined by near-infrared spectroscopy at a commercial feed-testing laboratory (Eurofins Steins Laboratorium A/S, Holstebro, Denmark). On the day of sampling, $300 \mathrm{~g}$ of silage was double bagged in plastic bags and frozen at $-20^{\circ} \mathrm{C}$. At the end of the sampling week, all samples from the respective sampling period were shipped to the feed-testing laboratory.

\section{Data Collection for Dietary Composition and Milk Yield}

Test-day weighing of ration ingredients and milk yield were carried out according to routine management procedures for Danish dairy farms participating in programs on dairy nutrition and management (Landscentret, Aarhus, Denmark) and in the national milk testing program (RYK, Aarhus, Denmark). Milk and ration composition data were obtained from the Danish national cattle and milk yield databases (Landscentret, Aarhus, Denmark), where all Danish dairy farms are registered with a unique identity. Milk samples were analyzed for fat, protein, and lactose by infrared spectrometry using a Milko Scan 4000 (Eurofins Steins A/S, Holstebro, Denmark). Forage DM contents were determined by drying for $48 \mathrm{~h}$ at $60^{\circ} \mathrm{C}$ (Eurofins Steins A/S, Holstebro, Denmark).

\section{Calculations and Statistical Procedures}

Contents of substrates and fermentation products in silage extracts were calculated as grams of extract per kilogram of DM corrected for DM content of silage sample $\times$ molar concentration of compound in extract $\times$ molecular weight of compound. The molecular weights used were the weights of the free acids including hydrolysis water for AA.

Data on fermentation variables, microbial contents, toxin contents, and aerobic stability were analyzed using the MIXED procedure in SAS [Statistical Analysis System version 9.1 (TS1M3), SAS Institute Inc., Cary, $\mathrm{NC}$. The model included the fixed effects of treatment and sampling time as well as their interaction. Contractor, contractor by treatment, and farm by treatment were included as random effects, and sampling time was considered as a repeated measure using compound symmetry as covariate structure.

Data on silage temperature in bunkers were analyzed using the model described for fermentation variables except that silage height and silage height by sampling time were included as covariates. The CORR procedure in SAS was used to calculate correlations between vari- ables. Microbial counts and DM differences between plant samples and FM and between FM and silage were compared by paired $t$-tests computed by the MEANS procedure in SAS. The Mixed procedure was used for regression analysis of silage DM on FM DM and aerobic stability on fermentation variables.

Milk yield data were obtained for 38 herds. The expected milk yield of cows within herd was predicted by a herd-specific model based on test-day results from 2007 and 2008. The model included the fixed effects of breed (Holstein, Danish Red, Jersey, and crosses), days in milk (10 levels), parity (1, 2, and $3+$ ), and calving season (spring, fall), and the random effect of cow. The milk yield data and residual milk yield based on the model above were averaged within herd for three 2-mo periods: January and February as related to silage collected in January, April and May as related to silage collected in April, and August and September as related to silage collected in August. Milk yield and residual milk yield data were analyzed by the model described for silage variables.

Data are presented as least squares means \pm residual error of the mean. Significance was declared at $P \leq$ 0.05 , and tendencies were considered at $0.05<P \leq$ 0.10 . The PDIFF option of the LSMEANS procedure was used to separate treatment means within sampling time protected by the overall $F$-test.

\section{RESULTS AND DISCUSSION}

\section{Ensiling Conditions}

Ensiling conditions were homogenous between treatments with respect to number of farms per treatment; area harvested per farm; DM content; and counts of LAB, yeast, mold, and coliforms (Table 1). The DM contents determined on FM obtained from the bunkers ranged from 28.5 to $46.5 \% \mathrm{DM}$, with an average of $34.5 \pm 0.8 \%$, and were in line with the general recommendations for corn to be ensiled in horizontal silos (Roth et al., 1995). Both the total counts and the relative abundance of LAB, yeast, and coliforms were in line with previous reports on the epiphytic microflora of corn (Lin et al., 1992). Samples obtained from the bunkers had substantially greater counts of LAB, yeast, and coliforms than plant samples as has generally been observed (Kroulik et al., 1955; McDonald et al., 1991). The total LAB counts in the FM samples from bunkers were 3 to 5 times the inoculation doses, which might be the primary reason for our inability $(P=0.20)$ to detect increasing LAB counts in inoculated silages and could affect the ability of a homofermentative inoculant closely related to the epiphytic flora to affect silage fermentation. 
Table 1. Number of farms per treatment, average corn area per farm, DM content at harvest, and microbial composition of corn plants sampled at harvest and chopped green crop sampled from silage bunkers

\begin{tabular}{|c|c|c|c|c|c|}
\hline Item $^{1}$ & \multicolumn{3}{|c|}{ Inoculation treatment } & SEM & $P$-value ${ }^{2}$ \\
\hline Corn area per farm, ha & 55.8 & 61.3 & 49.9 & 6.7 & 0.49 \\
\hline DM content of plant samples, ${ }^{3,4} \%$ & 34.2 & 35.0 & 34.3 & 1.1 & 0.80 \\
\hline DM content of FM from bunker, $\%$ & 33.1 & 33.5 & 33.5 & 0.9 & 0.91 \\
\hline LAB in plant samples, ${ }^{3,4} \log _{10} \mathrm{cfu} / \mathrm{g}$ & 4.56 & 4.37 & 4.94 & 0.29 & 0.20 \\
\hline Yeast in FM from bunker, $\log _{10} \mathrm{cfu} / \mathrm{g}$ & 6.36 & 6.52 & 6.51 & 0.12 & 0.41 \\
\hline Molds in plant samples ${ }^{3} \log _{10} \mathrm{cfu} / \mathrm{g}$ & 5.71 & 5.45 & 5.60 & 0.12 & 0.36 \\
\hline Molds in FM from bunker, $\log _{10} \mathrm{cfu} / \mathrm{g}$ & 5.64 & 5.64 & 5.75 & 0.09 & 0.58 \\
\hline Coliforms in plant samples, ${ }^{3,4} \log _{10} \mathrm{cfu} / \mathrm{g}$ & 6.33 & 6.67 & 6.60 & 0.27 & 0.65 \\
\hline Coliforms in FM from bunker, $\log _{10} \mathrm{cfu} / \mathrm{g}$ & 7.07 & 7.20 & 7.04 & 0.17 & 0.73 \\
\hline
\end{tabular}

${ }^{1} \mathrm{FM}=$ fresh matter; LAB = lactic acid bacteria.

${ }^{2}$ Probability for difference between treatments.

${ }^{3}$ Corn plants were harvested in the field at time of ensiling at 24 farms.

${ }^{4}$ Values for plant samples and samples of FM obtained from the bunker during harvest differed $(P \leq 0.05)$.

\section{Silage DM}

The DM content after ensiling was not affected by treatment $(P=0.27)$; however, the DM content of silage was greater $(P<0.01 ; 2.8 \pm 0.4$ percent unit increase) than the DM content of the FM samples. The difference between silage DM percent (DM\%) and FM DM\% was affected $(P<0.01)$ by FM DM\%. The difference was $-0.62 \pm 0.08 \times \mathrm{FM} \mathrm{DM} \%+23.6 \pm 2.6$ as estimated by regression of the difference silage DM\% - FM DM\% on FM DM\%. Usually silage fermentation produces volatile compounds (Porter and Murray, 2001) that often will cause the apparent DM\% of silage to decrease as compared with FM. Factors such as runoff, use of absorbents, and DM gradient in the bunker, meaning that the content with greatest moisture content at the bottom is underrepresented in the samples, may have contributed to the observed increase in silage DM. However, the drilling method might also squeeze fluid out of the material during collection and thereby contribute to the relatively greater DM\% of silage from moist crop.

\section{Silage Fermentation Variables}

We could not detect any effects of inoculation with Lactisil on silage $\mathrm{pH}$ or any of the measured fermentation variables (Table 2). The only exception was the interaction $(P=0.03)$ between treatment and time for ethanol, reflecting a lesser initial ethanol content with Lactisil and that the ethanol content showed a relatively larger increase with time for this treatment. However, this apparent effect of Lactisil was isolated and numerically small compared with the generally profound effects $(P<0.01)$ of inoculation with Lalsil Fresh observed for all measured fermentation variables except butyric acid and ethanol.

Silage $p H$, Lactic Acid, and VFA. Lalsil Fresh increased $(P<0.01)$ silage $\mathrm{pH}$, and the overall difference between Lalsil Fresh and the other treatments was $0.23 \pm 0.03 \mathrm{pH}$ units. This effect of Lalsil Fresh is consistent with previous reports on effects of inoculation with L. buchneri in laboratory-scale systems (Kleinschmit and Kung, 2006), although no pH effect was observed in a previous observational field study (Mari et al., 2009). In line with the former meta-analysis, the observed increase in $\mathrm{pH}$ followed a decreased $(P<0.01)$ concentration of lactic acid (L and D $+\mathrm{L}$ isomers) and increased $(P<0.01)$ contents of acetic and propionic acid. Predictions of silage $\mathrm{pH}$ by a regression model based on contents of DL-lactic, acetic, and propionic acids showed a high correlation $(\mathrm{r}=0.83)$ with observed $\mathrm{pH}$. Inclusion of ammonia and free AA (see below) in the regression model further improved the fit of the model $(\mathrm{r}=0.88)$. However, silage samples obtained in April did seem to have greater $\mathrm{pH}$ than expected from the measured fermentation variables, and time (class variable with 3 levels) was affecting $(P<0.01)$ the relationship between the fermentation variables and $\mathrm{pH}$. The fit of the model was improved $(\mathrm{r}=0.95)$ with time included. It can be concluded that a linear combination of major fermentation variables that participate in proton binding or release reactions explain by far the largest part of the differences in $\mathrm{pH}$ of silages inoculated with Lalsil Fresh compared with control and Lactisil. However, compounds not accounted for, that might include other AA or amines, contributed to the effect of Lalsil Fresh on silage $\mathrm{pH}$. 
Table 2. Dry matter content, $\mathrm{pH}$, content of fermentation products, content of substrates, microbial composition, aerobic stability, and content of Fusarium toxins in silage samples collected in January, April, and August 2009

\begin{tabular}{|c|c|c|c|c|c|c|c|c|c|c|c|c|c|}
\hline \multirow[b]{2}{*}{ Item } & \multicolumn{3}{|c|}{ January } & \multicolumn{3}{|c|}{ April } & \multicolumn{3}{|c|}{ August } & \multirow[b]{2}{*}{ SEM } & \multicolumn{3}{|c|}{$P$-value ${ }^{1}$} \\
\hline & Control & Lactisil & Lalsil Fresh & Control & Lactisil & Lalsil Fresh & Control & Lactisil & Lalsil Fresh & & Trt & $\begin{array}{l}\text { Trt } \times \\
\text { Time }\end{array}$ & Time \\
\hline DM content, $\%$ & 35.9 & 36.7 & 35.2 & 36.2 & 36.3 & 35.5 & 36.7 & 37.2 & 35.9 & 0.7 & 0.27 & 0.91 & 0.11 \\
\hline \multicolumn{14}{|c|}{ Fermentation variables, $\mathrm{g} / \mathrm{kg}$ of $\mathrm{DM}$} \\
\hline Silage $\mathrm{pH}$ & $3.81^{\mathrm{a}}$ & $3.82^{\mathrm{a}}$ & $3.97^{\mathrm{b}}$ & $3.90^{\mathrm{a}}$ & $3.94^{\mathrm{a}}$ & $4.19^{\mathrm{b}}$ & $3.80^{\mathrm{a}}$ & $3.79^{\mathrm{a}}$ & $4.05^{\mathrm{b}}$ & 0.03 & $<0.01$ & 0.12 & $<0.01$ \\
\hline L-Lactic acid & $26.4^{\mathrm{a}}$ & $26.4^{\mathrm{a}}$ & $19.0^{\mathrm{b}}$ & $30.1^{\mathrm{a}}$ & $29.2^{\mathrm{a}}$ & $14.6^{\mathrm{b}}$ & $27.8^{\mathrm{a}}$ & $29.0^{\mathrm{a}}$ & $14.5^{\mathrm{b}}$ & 1.8 & $<0.01$ & 0.02 & 0.71 \\
\hline DL-Lactic acid & $48.7^{\mathrm{a}}$ & $47.9^{\mathrm{a}}$ & $36.1^{\mathrm{b}}$ & $56.2^{\mathrm{a}}$ & $55.7^{\mathrm{a}}$ & $32.4^{\mathrm{b}}$ & $56.2^{\mathrm{a}}$ & $55.5^{\mathrm{a}}$ & $31.5^{\mathrm{b}}$ & 3.2 & $<0.01$ & 0.07 & 0.15 \\
\hline Acetic acid & $15.5^{\mathrm{a}}$ & $13.9^{\mathrm{a}}$ & $25.4^{\mathrm{b}}$ & $15.5^{\mathrm{a}}$ & $14.1^{\mathrm{a}}$ & $34.5^{\mathrm{b}}$ & $17.1^{\mathrm{a}}$ & $15.3^{\mathrm{a}}$ & $36.5^{\mathrm{b}}$ & 1.6 & $<0.01$ & $<0.01$ & $<0.01$ \\
\hline Propionic acid & 0.16 & 0.09 & 0.67 & $0.08^{\mathrm{a}}$ & $0.09^{\mathrm{a}}$ & $1.74^{\mathrm{b}}$ & $0.27^{\mathrm{a}}$ & $0.10^{\mathrm{a}}$ & $2.33^{\mathrm{b}}$ & 0.21 & $<0.01$ & $<0.01$ & $<0.01$ \\
\hline Butyric acid & 0.017 & 0.016 & 0.019 & 0.020 & 0.024 & 0.025 & 0.031 & 0.060 & 0.029 & 0.010 & 0.53 & 0.42 & 0.03 \\
\hline Ethanol & 10.9 & 7.9 & 9.0 & 9.4 & 10.0 & 9.9 & 9.6 & 11.2 & 10.3 & 1.2 & 0.98 & 0.03 & 0.18 \\
\hline Propanol & 0.72 & 0.44 & 2.43 & $0.62^{\mathrm{a}}$ & $0.60^{\mathrm{a}}$ & $4.94^{\mathrm{b}}$ & $2.02^{\mathrm{a}}$ & $0.61^{\mathrm{a}}$ & $7.16^{\mathrm{b}}$ & 0.68 & $<0.01$ & 0.01 & $<0.01$ \\
\hline Propyl acetate & 0.33 & 0.12 & 1.51 & $0.26^{\mathrm{a}}$ & $0.22^{\mathrm{a}}$ & $3.83^{\mathrm{b}}$ & $0.96^{\mathrm{a}}$ & $0.24^{\mathrm{a}}$ & $5.05^{\mathrm{b}}$ & 0.45 & $<0.01$ & $<0.01$ & $<0.01$ \\
\hline 2-Butanol & $0.005^{\mathrm{a}}$ & $0.011^{\mathrm{a}}$ & $0.089^{\mathrm{b}}$ & $0.009^{\mathrm{a}}$ & $0.009^{\mathrm{a}}$ & $0.099^{\mathrm{b}}$ & $0.045^{\mathrm{a}}$ & $0.017^{\mathrm{a}}$ & $0.150^{\mathrm{b}}$ & 0.024 & $<0.01$ & 0.66 & 0.03 \\
\hline Propylene glycol & $1.35^{\mathrm{a}}$ & $1.36^{\mathrm{a}}$ & $8.47^{\mathrm{b}}$ & $1.29^{\mathrm{a}}$ & $0.97^{\mathrm{a}}$ & $8.20^{\mathrm{b}}$ & $0.98^{\mathrm{a}}$ & $1.40^{\mathrm{a}}$ & $8.20^{\mathrm{b}}$ & 1.0 & $<0.01$ & 0.98 & 0.87 \\
\hline Ammonia & 0.62 & 0.62 & 0.70 & $0.84^{\mathrm{a}}$ & $0.90^{\mathrm{a}}$ & $1.07^{\mathrm{b}}$ & $0.94^{\mathrm{a}}$ & $0.95^{\mathrm{a}}$ & $1.13^{\mathrm{b}}$ & 0.04 & $<0.01$ & 0.14 & $<0.01$ \\
\hline Alanine & 3.13 & 2.98 & 3.67 & $3.50^{\mathrm{a}}$ & $3.58^{\mathrm{a}}$ & $4.54^{\mathrm{b}}$ & $3.87^{\mathrm{a}}$ & $3.55^{\mathrm{a}}$ & $4.71^{\mathrm{b}}$ & 0.24 & $<0.01$ & 0.39 & $<0.01$ \\
\hline Glycine & $1.08^{\mathrm{a}}$ & $1.11^{\mathrm{a}}$ & $1.31^{\mathrm{b}}$ & $1.19^{\mathrm{a}}$ & $1.23^{\mathrm{a}}$ & $1.49^{\mathrm{b}}$ & $1.23^{\mathrm{a}}$ & $1.23^{\mathrm{a}}$ & $1.64^{\mathrm{b}}$ & 0.05 & $<0.01$ & 0.10 & $<0.01$ \\
\hline Isoleucine & 0.92 & 0.89 & 0.91 & $0.98^{\mathrm{a}}$ & $1.00^{\mathrm{a}}$ & $1.18^{\mathrm{b}}$ & $1.07^{\mathrm{a}}$ & $1.06^{\mathrm{a}}$ & $1.33^{\mathrm{b}}$ & 0.05 & $<0.01$ & 0.01 & $<0.01$ \\
\hline Leucine & 2.69 & 2.71 & 2.88 & $3.11^{\mathrm{a}}$ & $3.23^{\mathrm{a}}$ & $3.73^{\mathrm{b}}$ & $3.43^{\mathrm{a}}$ & $3.51^{\mathrm{a}}$ & $4.13^{\mathrm{b}}$ & 0.14 & $<0.01$ & 0.21 & $<0.01$ \\
\hline Proline & 1.89 & 1.91 & 1.96 & $2.22^{\mathrm{a}}$ & $2.21^{\mathrm{a}}$ & $2.52^{\mathrm{b}}$ & $2.40^{\mathrm{a}}$ & $2.47^{\mathrm{a}}$ & $2.95^{\mathrm{b}}$ & 0.10 & $<0.01$ & 0.04 & $<0.01$ \\
\hline Valine & $1.30^{\mathrm{a}}$ & $1.28^{\mathrm{a}}$ & $1.45^{\mathrm{b}}$ & $1.41^{\mathrm{a}}$ & $1.45^{\mathrm{a}}$ & $1.78^{\mathrm{b}}$ & $1.50^{\mathrm{a}}$ & $1.51^{\mathrm{a}}$ & $1.94^{\mathrm{b}}$ & 0.06 & $<0.01$ & 0.01 & $<0.01$ \\
\hline Glucose & $1.98^{\mathrm{a}}$ & $1.27^{\mathrm{a}}$ & $0.46^{\mathrm{b}}$ & $2.92^{\mathrm{a}}$ & $2.52^{\mathrm{a}}$ & $0.57^{\mathrm{b}}$ & $2.82^{\mathrm{a}}$ & $3.77^{\mathrm{a}}$ & $0.71^{\mathrm{b}}$ & 0.58 & $<0.01$ & 0.27 & 0.03 \\
\hline Benzoic acid & 0.006 & 0.012 & 0.011 & 0.014 & 0.017 & 0.019 & 0.009 & 0.005 & 0.011 & 0.004 & 0.51 & 0.69 & 0.02 \\
\hline \multicolumn{14}{|l|}{ Metabolite ratios } \\
\hline $\begin{array}{l}\text { L-Lactic acid: } \\
\text { DL-lactic acid }\end{array}$ & 0.54 & 0.55 & 0.53 & $0.54^{\mathrm{a}}$ & $0.53^{\mathrm{a}}$ & $0.44^{\mathrm{b}}$ & $0.49^{\mathrm{a}, \mathrm{b}}$ & $0.52^{\mathrm{a}}$ & $0.45^{\mathrm{b}}$ & 0.02 & 0.01 & 0.09 & $<0.01$ \\
\hline $\begin{array}{l}\text { DL-Lactic acid: } \\
\text { acetic acid }\end{array}$ & $3.35^{\mathrm{a}}$ & $3.60^{\mathrm{a}}$ & $1.70^{\mathrm{b}}$ & $3.72^{\mathrm{a}}$ & $4.03^{\mathrm{a}}$ & $1.12^{\mathrm{b}}$ & $3.66^{\mathrm{a}}$ & $3.67^{\mathrm{a}}$ & $0.96^{\mathrm{b}}$ & 0.27 & $<0.01$ & 0.10 & 0.59 \\
\hline \multicolumn{14}{|c|}{ Microbial contents, $\log _{10} \mathrm{cfu} / \mathrm{g}$} \\
\hline $\mathrm{LAB}^{2}$ & 7.08 & 7.05 & 7.39 & $7.16^{\mathrm{a}}$ & $7.21^{\mathrm{a}}$ & $8.39^{\mathrm{b}}$ & $7.10^{\mathrm{a}}$ & $6.69^{\mathrm{a}}$ & $7.80^{\mathrm{b}}$ & 0.24 & $<0.01$ & 0.13 & 0.03 \\
\hline Yeast & $6.45^{\mathrm{a}}$ & $6.27^{\mathrm{a}}$ & $4.91^{\mathrm{b}}$ & 6.09 & 6.24 & 5.43 & $4.97^{\mathrm{a}}$ & $5.00^{\mathrm{a}}$ & $3.34^{\mathrm{b}}$ & 0.34 & $<0.01$ & 0.57 & $<0.01$ \\
\hline Molds & 3.44 & $<3.00$ & 3.00 & 3.78 & 3.64 & 4.09 & 3.01 & 3.35 & 3.17 & 0.24 & 0.86 & 0.31 & $<0.01$ \\
\hline \multicolumn{14}{|c|}{ Silage temperature and aerobic stability } \\
\hline $\begin{array}{l}\text { Silage temperature } \\
\text { in bunker, }{ }^{\circ} \mathrm{C}\end{array}$ & 18.3 & 17.8 & 18.8 & $15.0^{\mathrm{a}}$ & $15.2^{\mathrm{a}}$ & $16.8^{\mathrm{b}}$ & $16.9^{\mathrm{a}}$ & $17.6^{\mathrm{ab}}$ & $18.6^{\mathrm{b}}$ & 1.0 & 0.02 & 0.84 & $<0.01$ \\
\hline Aerobic stability, h & $39^{\mathrm{a}}$ & $37^{\mathrm{a}}$ & $88^{\mathrm{b}}$ & 36 & 33 & 53 & $37^{\mathrm{a}}$ & $43^{\mathrm{a}}$ & $100^{\mathrm{b}}$ & 9 & $<0.01$ & 0.01 & 0.06 \\
\hline \multicolumn{14}{|c|}{ Fusarium toxins, $\mu \mathrm{g} / \mathrm{kg}$ of $\mathrm{DM}$} \\
\hline Deoxynivalenol & 592 & 532 & 653 & 714 & 574 & 634 & 503 & 553 & 631 & 128 & 0.80 & 0.85 & 0.65 \\
\hline Nivalenol & 177 & 254 & 303 & 227 & 338 & 297 & 268 & 270 & 187 & 80 & 0.73 & 0.29 & 0.44 \\
\hline Zearalenone & 15 & 42 & 43 & 52 & 58 & 25 & 35 & 90 & 57 & 30 & 0.52 & 0.70 & 0.39 \\
\hline
\end{tabular}


A treatment-by-time interaction $(P=0.02)$ was observed for the content of L-lactic acid reflecting an increased content in April and August with the control and Lactisil compared with a decreased content with Lalsil Fresh. A similar trend $(P=0.07)$ was also observed for DL-lactic acid content. Strong interactions $(P$ $<0.01$ ) between treatment and time were observed for acetic and propionic acid contents reflecting a relatively large increase in concentration with time for Lalsil Fresh compared with lesser and relatively stable contents for the other treatments. The observed increase in acetic and propionic acid with Lalsil Fresh is in line with the general findings of effects of inoculation with L. buchneri (Kleinschmit and Kung, 2006), although these effects were not observed in an observational field study (Mari et al., 2009), which partly could have been caused by untreated silages in the field study being more heterofermentative in nature (greater acetic and propionic acid contents) compared with the control and Lactisil-treated silages in the present study. The butyric acid contents of silages were not affected by treatment in the present study.

Alcohols, Propyl Acetate, and Propylene Glycol. The contents of propanol, propyl acetate, 2-butanol, and propylene glycol increased $(P<0.01)$ with Lalsil Fresh compared with the 2 other treatments. The treatment difference for propanol increased with time $(P=0.01)$ reflecting that the propanol content with Lalsil Fresh did not differ from the other treatments in January but increased to a level 5 times the average content of control and Lactisil in samples collected in August. The appearance of propanol has previously been observed in silage treated with L. buchneri (Driehuis et al., 1999; Driehuis et al., 2001) and in naturally heterofermented corn silage (Kristensen et al., 2007). The content of the acetate ester of propanol, propyl acetate, correlated strongly $(\mathrm{r}=0.86, \mathrm{r}=0.93$, and $\mathrm{r}$ $=0.98 ; P<0.01)$ with the contents of acetic acid, propionic acid, and propanol and can be expected to contribute to the chemical flavor of heterofermented silages due to its volatility. The presence of propyl acetate was also previously observed in heterofermented corn silage (Kristensen et al., 2007). The presence of derivatives of alcohols and VFA in silages makes it difficult to attribute a special causal effect to the contents of acetic acid in heterofermented corn silages with regard to stability traits. In addition, the low-molecular-weight esters and other organic acids might have important biological activity (Fredlund et al., 2004). Studies applying pure propanol to silages might fail to induce some of the secondary effects of propanol fermentation (Danner et al., 2003) because the more complex fermentation pattern reflecting secondary and tertiary fermentation products is not allowed to proceed as it would if propanol were produced by fermentation in the silage.

The propylene glycol content of silages treated with Lalsil Fresh was greater $(P<0.01)$ compared with the content in control and Lactisil silages (overall difference $7 \pm 1 \mathrm{~g} / \mathrm{kg}$ of $\mathrm{DM})$. The content of propylene glycol did not change $(P=0.87)$ with time. It is likely that the propanol and the propanol moiety of propyl acetate originate from propylene glycol degradation in the silage (Krooneman et al., 2002) in line with both ruminal and waste-water degradation of propylene glycol (Czerkawski and Breckenbridge, 1973; Veltman et al., 1998). Propanol was not present in L. buchneriinoculated grass silage after $60 \mathrm{~d}$ of ensiling but was present in substantial amounts after 119 d of ensiling, in line with the need for time to allow for growth of propylene glycol-degrading bacteria (Driehuis et al., 2001).

The content of 2-butanol increased $(P<0.01)$ with Lalsil Fresh treatment. The 2-butanol could originate from degradation of 2,3-butanediol by a pathway similar to propylene glycol degradation, and both compounds might depend on the same microbes for degradation (Radler and Zorg, 1986). The content of 2-butanol correlated poorly with any of the fermentation products characterizing heterofermentation. It is possible that the diacetyl production, the substrate for 2,3-butanediol (McDonald et al., 1991), does not differ between treatments but the metabolism of 2,3-butanediol differs due to increased activity of the pathway for degradation due to increased propylene glycol degradation. We did not assess the diacetyl content in the silages, and only trace amounts of 2,3-butanediol were detected.

Ammonia and Free $\boldsymbol{A} \boldsymbol{A}$. The ammonia content of silages increased with time $(P<0.01)$ for all treatments and was greater $(P<0.01)$ with Lalsil Fresh compared with the 2 other treatments (overall difference $0.16 \pm$ $0.04 \mathrm{~g} / \mathrm{kg}$ of DM; Table 2). Generally, inoculation with L. buchneri has not been observed to increase ammonia content of silages (Kleinschmit and Kung, 2006; Mari et al., 2009), although an increase in ammonia content was observed in grass silage (Driehuis et al., 2001). However, studies that did not show effects of $L$. buchneri on ammonia content were of relatively short duration compared with the full feeding season represented in the present study. Our inability to separate treatments in January is, therefore, in line with the results of the previous studies. Thus, the prolonged fermentation phase of silages inoculated with L. buchneri seems to induce more extensive protein degradation in these silages as evaluated by the increased ammonia and free AA content. All free AA determined in silage extracts were observed in increasing amounts with Lal- 
sil Fresh compared with the 2 other treatments $(P<$ 0.01). The AA contents mirrored the ammonia content with small differences between treatments in January and more pronounced effects at the 2 later samplings, although a treatment-by-time interaction was only observed for isoleucine, proline, and valine $(P=0.04$ to $P$ $=0.01)$. Ammonia and the free AA determined in the present study accounted for $19.4 \pm 0.3 \%$ of total $\mathrm{N}$ in the silages and was $2.7 \pm 0.6$ percent units greater with Lalsil Fresh compared with the other 2 treatments.

Glucose and Benzoic Acid. The free glucose contents in the silages was greater $(P<0.01)$ with control and Lactisil compared with Lalsil Fresh and increased with time $(P=0.03)$. Data indicate a slow, continuous release of glucose and decreasing demand as fermentation was inhibited by accumulation of fermentation products including lactic acid. Analysis of benzoic acid was included as a test for any ex-protocol use of additives by farmers that would be expected to have a major effect on silage stability (Kleinschmit et al., 2005). We did not observe any indication of use of benzoic acid-based additives in the tested silages.

Lactic Acid and Acetic Acid Ratios. The L-lactic acid to DL-lactic acid ratio was less for Lalsil Fresh compared with the other 2 treatments and decreased $(P<0.01)$ for all treatments from $0.54 \pm 0.01$ in January to $0.49 \pm 0.01$ in August. These minor effects on lactic acid isomers might be indicative of greater affinity of L. buchneri for degradation of L-lactic acid but are likely without physiological effect on ruminants due to the rapid ruminal degradation of lactic acid to VFA (Chamberlain et al., 1983). The ratio of DL-lactic acid to acetic acid was affected $(P<0.01)$ by Lalsil Fresh compared with the 2 other treatments. The ratio for silages treated with Lalsil Fresh averaged $1.3 \pm 0.2$ compared with $3.7 \pm 0.2$ for the 2 other treatments, and this ratio was not affected by time $(P=0.59)$. This shift in DL-lactic acid to acetic acid ratio was not observed in the field study by Mari et al. (2009) but was observed in the meta-analysis of laboratory-scale studies (Kleinschmit and Kung, 2006). The imposed changes in DL-lactic acid to acetic acid violate the classic approach to good silage quality aiming at the greatest possible lactic acid contents (Weinberg and Muck, 1996). However, the recommendation to aim for homofermentative silages seems largely to be derived from work on grass silages in which fermentation has been shown to affect silage intake (Thomas and Thomas, 1985). Feeding barley silage treated with L. buchneri did not negatively affect production traits of dairy cows (Taylor et al., 2002), and DM intake of cows fed a TMR based on heterofermented corn silage was not affected (Kristensen et al., 2007). As proposed by Kleinschmit and Kung (2006), the relationships between silage fer- mentation and feed intake might not be comparable in grass and legume silages versus corn and small grain silages, and therefore, the use of DL-lactic acid to acetic acid ratios in assessing corn silage quality warrants a more extensive reevaluation.

\section{Microbial Counts}

Total LAB counts increased with time $(P=0.03)$ and were greater with Lalsil Fresh $(P<0.01)$. We could not detect any interaction between treatment and time $(P=0.13)$, although the numerical differences between Lalsil Fresh and the other 2 treatments appeared to increase with time. The prolonged fermentation activity in heterofermented silages is in agreement with the greater LAB counts in these silages, and Driehuis et al. (1999) observed that L. buchneri dominated the LAB population from d 28 of ensiling when silages were inoculated with this bacterium. Yeast counts decreased with time $(P<0.01)$ and were less $(P<0.01)$ with Lalsil Fresh compared with the 2 other treatments. Although no interaction $(P=0.57)$ was observed, differences between treatments appeared smaller in April compared with differences in January and August. We could not detect differences between treatments with respect to counts of molds, but counts were greater $(P$ $<0.01$ ) in April compared with January and August. The decrease in yeast counts with Lalsil Fresh was expected. Indeed, the original interest in L. buchneri as a silage inoculant was based on the presumed increased stability of corn silage partly through inhibition of yeast growth in these silages (Weinberg and Muck, 1996; Driehuis et al., 1999), consistent with the results of the meta-analysis by Kleinschmit and Kung (2006).

\section{Silage Temperature and Aerobic Stability}

The silage temperature in the center and $1 \mathrm{~m}$ behind the face was measured to assess the extent to which stability and fermentation variables could have been affected by aerobic deterioration in the bunkers. This seemed not to have been the case at any of the visited farms because the highest measured temperature was $23.6^{\circ} \mathrm{C}$ and temperatures measured in the bunkers were not $(P>0.10)$ correlated with aerobic stability. The bunker temperature increased $(P=0.02)$ with Lalsil Fresh compared with the 2 other treatments in April, and Lalsil Fresh also differed from the control in August, which might be the result of the prolonged fermentation in the heterofermented silages.

The aerobic stability of Lalsil Fresh-inoculated silages increased $(P<0.01)$, with an overall difference between Lalsil Fresh and the 2 other treatments of 43 $\pm 8 \mathrm{~h}$, thereby more than doubling the stability. How- 
Table 3. Nutrient composition of corn silages, corn silage of total dietary DM, herd size, and production traits for dairy cows at the involved farms from January to September 2009

\begin{tabular}{|c|c|c|c|c|c|}
\hline \multirow[b]{2}{*}{ Item } & \multicolumn{3}{|c|}{ Inoculation treatment } & \multirow[b]{2}{*}{ SEM } & \multirow[b]{2}{*}{$P$-value ${ }^{1}$} \\
\hline & Control & Lactisil & Lalsil Fresh & & \\
\hline Starch content, $\mathrm{g} / \mathrm{kg}$ of $\mathrm{DM}$ & 328 & 335 & 341 & 8 & 0.33 \\
\hline $\mathrm{CP}$ content, $\mathrm{g} / \mathrm{kg}$ of $\mathrm{DM}$ & $72.1^{\mathrm{a}}$ & $72.8^{\mathrm{a}}$ & $76.3^{\mathrm{b}}$ & 0.8 & $<0.01$ \\
\hline Corn silage of total dietary DM, \% & 0.42 & 0.37 & 0.39 & 0.03 & 0.14 \\
\hline Lactating cows on test days, $\mathrm{n}$ & 162 & 191 & 145 & 19 & 0.24 \\
\hline
\end{tabular}

${ }^{\mathrm{a}, \mathrm{b}}$ Different superscripts within a row indicate that values differ $(P<0.05)$.

${ }^{1}$ Probability for difference between treatments.

${ }^{2} \mathrm{ECM}, 3.14 \mathrm{MJ} / \mathrm{kg}$.

ever, a treatment-by-time interaction $(P=0.01)$ was observed, reflecting that the difference between Lalsil Fresh and the 2 other treatments was less in samples collected in April. The relationship between fermentation variables and the observed variation in the efficacy of Lalsil Fresh to increase stability at different sampling times is not immediately evident from means presented in Table 2. A stepwise reduction of a regression model containing all variables in Table 2 initially retaining parameters with $P<0.15$ resulted in a model containing only yeast, acetic acid, LAB, 2-butanol, propylene glycol, alanine, and isoleucine, although care should be taken not to overinterpret this simple model. Overall, data are in agreement with increased stability of Lalsil Fresh-treated silage because of inhibition of yeast growth. Generally yeast play an important role in aerobic deterioration of silage. However, the most important exception might be situations in which yeast growth is inhibited and the silage environment is open for growth of Acetobacter and other bacteria that may participate in aerobic deterioration (Woolford, 1990). We did not enumerate the population of Acetobacter in the collected silages or during stability tests, but this question warrants further investigation.

\section{Fusarium Toxins}

The content of the Fusarium toxins was not affected by treatment $(P=0.52$ to $P=0.80)$ or sampling time $(P=0.39$ to $P=0.65$; Table 2$)$. The content of HT-2 only exceeded the limit of detection $(10 \mu \mathrm{g} / \mathrm{kg}$ of DM $)$ in a few samples, and T-2 and fumonisins (FB1 and FB2, determined in samples collected in January) were not detected in any of the samples. Dairy cows generally show no or very limited response to feed containing Fusarium toxins (Trenholm et al., 1985; Charmley et al., 1993). However, mycotoxins and mycotoxicosis attract considerable attention among producers. Data presented by Boudra and Morgavi (2008) indicated that deoxynivalenol contents of corn silage decreased during storage, which was in contrast to our findings of relatively constant Fusarium toxin contents during the entire collection period, suggesting that one cannot rely on ensiling to solve a Fusarium infection problem in corn.

\section{Nutrient Content of Silage and Milk Production}

In vitro DM digestibility and starch content of silages did not differ among treatments $(P=0.21$ and $P=$ 0.33 ; Table 3). Crude protein content was found to be greater $(P<0.01)$ with Lalsil Fresh compared with the 2 other treatments. However, it is not known whether this is an artifact of the near-infrared spectroscopy method potentially caused by the greater concentration of free AA in the Lalsil Fresh-treated silages (Table 2 ). Nevertheless, we do not expect that this relatively small difference in $\mathrm{CP}$ compared with the $\mathrm{CP}$ content of the offered rations could have affected treatment effects on milk production. The proportion of corn silage DM to total ration DM (rations as fed) for lactating dairy cows in the herds did not differ $(P=0.14)$ among treatments.

The number of lactating cows per herd and the average milk production on test days did not differ $(P=$ 0.24 and $P=0.49$ ) among treatments. Milk production relative to the predicted milk yield within farm was not affected $(P=0.94)$. This study agrees with previous studies that suggested weak relationships between fermentation characteristics of corn silage and feed intake and milk production by dairy cows (Wohlt, 1989; Kung et al., 1993). The apparent lack of effect of corn silage fermentation on cattle performance could be caused by a greater resilience of dairy cattle toward fermentation phenomena in corn silage compared with the effect of grass silage fermentation, or by the fact that we inves- 
tigated a far from complete range of variables in silages and thereby overlooked variables of greater importance than the traditionally evaluated compounds.

\section{CONCLUSIONS}

Inoculation of corn silage with a homofermentative inoculant based on $L$. pentosus and $P$. pentosaceus (Lactisil) did not affect silage fermentation or aerobic stability compared with no inoculation, probably because this inoculant was relatively homologous to and outnumbered by the epiphytic microflora. Inoculation of corn silage with the heterofementative L. buchneri (Lalsil Fresh) increased aerobic stability, with an overall doubling in time of stability. L. buchneri inoculation increased silage $\mathrm{pH}$ and contents of acetic acid, propionic acid, propanol, propyl acetate, propylene glycol, free $\mathrm{AA}$, and ammonia and decreased lactic acid content in silages. Neither of the inoculation treatments affected milk production under field conditions compared with the control.

\section{ACKNOWLEDGMENTS}

We gratefully acknowledge Anne Krustrup, Pia Jensen, Marie Engbæk, Birgit H. Løth, Karin Durup, Thorkild N. Jakobsen, Ole H. Olsen, Torben Skræp, Dorthe N. Buus, and Birgitte M.L. Raun, Faculty of Agricultural Sciences, Aarhus University (Tjele, Denmark), for skillful technical assistance. We wish to thank all participating dairy farmers, contractors, and the local extension service staff for their patience in receiving information on treatments and help in conducting the study in the field. We wish to thank Anne Mette Kjeldsen (Danish Cattle Federation, Aarhus, Denmark) for extracting feed ration data from the Danish national cattle database. We thank Søren Hertzum (Erri-Comfort A/S, Skærbæk, Denmark) and Henrik Hansen (Lallemand Nordic, Kibæk, Denmark) for help in identifying contractors willing to participate in the study. Nonactive vehicle and Lactisil were provided for the study by Chr. Hansen A/S (Hørsholm, Denmark). Lalsil Fresh was provided for the study by Lallemand Animal Nutrition (Blagnac, France). We wish to thank Christer Ohlsson and Inge Knap (Chr. Hansen A/S, Hørsholm, Denmark) as well as Eric Chevaux and Julien Sindou (Lallemand Animal Nutrition, Blagnac, France) for fruitful discussions during the planning phase of the study. Funding for the study was provided by the Danish Cattle Federation (Aarhus, Denmark) and Faculty of Agricultural Sciences, Aarhus University.

\section{REFERENCES}

Bligh, E. G., and W. J. Dyer. 1959. A rapid method of total lipid extraction and purification. Can. J. Biochem. Physiol. 37:911917.
Boudra, H., and D. P. Morgavi. 2008. Reduction in Fusarium toxin levels in corn silage with low dry matter and storage time. J. Agric. Food Chem. 56:4523-4528.

Chamberlain, D. G., P. C. Thomas, and F. J. Anderson. 1983. Volatile fatty acid proportions and lactic acid metabolism in the rumen in sheep and cattle receiving silage diets. J. Agric. Sci. Camb. 101:47-58.

Charmley, E., H. L. Trenholm, B. K. Thompson, D. Vudathala, J. W. G. Nicholson, D. B. Prelusky, and L. L. Charmley. 1993. Influence of level of deoxynivalenol in the diet of dairy cows on feed intake, milk production, and its composition. J. Dairy Sci. 76:35803587.

Czerkawski, J. W., and G. Breckenbridge. 1973. Dissimilation of 1,2-propanediol by rumen micro-organisms. Br. J. Nutr. 29:317330 .

Danner, H., M. Holzer, E. Mayrhuber, and R. Braun. 2003. Acetic acid increases stability of silage under aerobic conditions. Appl. Environ. Microbiol. 69:562-567.

Driehuis, F., S. J. W. H. O. Elferink, and P. G. Van Wikselaar. 2001. Fermentation characteristics and aerobic stability of grass silage inoculated with Lactobacillus buchneri, with or without homofermentative lactic acid bacteria. Grass Forage Sci. 56:330343.

Driehuis, F., S. J. H. W. Oude Elferink, and S. F. Spoelstra. 1999. Anaerobic lactic acid degradation during ensilage of whole crop maize inoculated with Lactobacillus buchneri inhibits yeast growth and improves aerobic stability. J. Appl. Microbiol. 87:583-594.

Fredlund, E., U. Ä. Druvefors, N. Olstorpe, V. Passoth, and J. Schnürer. 2004. Influence of ethyl acetate production and ploidy on the anti-mould activity of Pichia anomala. FEMS Microbiol. Lett. 238:133-137.

Kleinschmit, D. H., and L. Kung Jr. 2006. A meta-analysis of the effects of Lactobacillus buchneri on the fermentation and aerobic stability of corn and grass and small-grain silages. J. Dairy Sci. 89:4005-4013.

Kleinschmit, D. H., R. J. Schmidt, and L. Kung Jr. 2005. The effects of various antifungal additives on the fermentation and aerobic stability of corn silage. J. Dairy Sci. 88:2130-2139.

Kristensen, N. B., A. Danfær, V. Tetens, and N. Agergaard. 1996. Portal recovery of intraruminally infused short-chain fatty acids in sheep. Acta Agric. Scand. Anim. Sci. 46:26-38.

Kristensen, N. B., S. G. Pierzynowski, and A. Danfær. 2000. Portaldrained visceral metabolism of 3-hydroxybutyrate in sheep. J. Anim. Sci. 78:2223-2228.

Kristensen, N. B., A. Storm, B. M. L. Raun, B. A. Røjen, and D. L. Harmon. 2007. Metabolism of silage alcohols in lactating dairy cows. J. Dairy Sci. 90:1364-1377.

Krooneman, J., F. Faber, A. C. Alderkamp, S. J. H. W. Oude Elferink, F. Driehuis, I. Cleenwerck, J. Swings, J. C. Gottschal, and M. Vancanneyt. 2002. Lactobacillus diolivorans sp. nov., a 1,2-propanediol-degrading bacterium isolated from aerobically stable maize silage. Int. J. Syst. Environ. Microbiol. 52:639-646.

Kroulik, J. T., L. A. Burkey, and H. G. Wiseman. 1955. The microbial populations of the green plant and of the cut forage prior to ensiling. J. Dairy Sci. 38:256-262.

Kung, L. Jr., J. H. Chen, E. M. Kreck, and K. Knutsen. 1993. Effect of microbial inoculants on the nutritive value of corn silage for lactating dairy cows. J. Dairy Sci. 76:3763-3770.

Lin, C., K. K. Bolsen, B. E. Brent, R. A. Hart, J. T. Dickersen, A. M. Feyerherm, and W. R. Aimutis. 1992. Epiphytic microflora on alfalfa and whole-plant corn. J. Dairy Sci. 75:2484-2493.

Mari, L. J., R. J. Schmidt, L. G. Nussio, C. M. Hallada, and L. Kung Jr. 2009. Short communication: An evaluation of the effectiveness of Lactobacillus buchneri 40788 to alter fermentation and improve the aerobic stability of corn silage in farm silos. J. Dairy Sci. 92:1174-1176.

McDonald, P., N. Henderson, and S. Heron. 1991. The Biochemistry of Silage. 2nd ed. Chalcombe Publications, Bucks, UK.

Miller, T. L., and M. J. Wolin. 1974. A serum bottle modification of the Hungate technique for cultivating obligate anaerobes. Appl. Microbiol. 27:985-987. 
Muck, R. E. 1988. Factors influencing silage quality and their implications for management. J. Dairy Sci. 71:2992-3002.

Muck, R. E. 1993. The role of silage additives in making high quality silage. Pages 106-116 in Silage Production From Seed to Animal, NRAES-67. Northeast Regional Agricultural Engineering Service, Cooperative Extension, Ithaca, NY.

Nicolaisen, M., S. Suproniené, L. K. Nielsen, I. Lazzaro, N. H. Spliid, and A. F. Justesen. 2009. Real-time PCR for quantification of eleven individual Fusarium species in cereals. J. Microbiol. Methods 76:234-240.

Porter, M. G., and R. S. Murray. 2001. The volatility of components of grass silage on oven drying and the inter-relationship between drymatter content estimated by different analytical methods. Grass Forage Sci. 56:405-411.

Radler, F., and J. Zorg. 1986. Characterization of the enzyme involved in formation of 2-butanol from meso-2,3-butanediol by lactic acid bacteria. Am. J. Enol. Vitic. 37:206-210.

Roth, G., D. Undersander, M. Allen, S. Ford, J. Harrison, C. Hunt, J. Lauer, R. Muck, and S. Soderlund. 1995. Corn Silage Production, Management, and Feeding. American Society of Agronomy Inc., Crop Science Society of America Inc., Soil Science Society of America Inc., USA.

Taylor, C. C., N. J. Ranjit, J. A. Mills, J. M. Neylon, and L. Kung Jr. 2002. The effect of treating whole-plant barley with Lactobacillus buchneri 40788 on silage fermentation, aerobic stability, and nutritive value for dairy cows. J. Dairy Sci. 85:1793-1800.

Thomas, C., and P. C. Thomas. 1985. Factors affecting the nutritive value of grass silages. Pages 223-256 in Recent Advances in Animal Nutrition-1985. W. Haresign and D. J. A. Cole, ed. Butterworths, London, UK.

Trenholm, H. L., B. K. Thompson, K. E. Hartin, R. Greenhalgh, and A. J. McAllister. 1985. Ingestion of vomitoxin (deoxynivalenol)contaminated wheat by nonlactating dairy cows. J. Dairy Sci. 68:1000-1005.

Veltman, S., T. Schoenberg, and M. S. Switzenbaum. 1998. Alcohol and acid formation during the anaerobic decomposition of propylene glycol under methanogenic conditions. Biodegradation 9:113-118.

Weinberg, Z. G., and R. E. Muck. 1996. New trends and opportunities in the development and use of inoculants for silage. FEMS Microbiol. Rev. 19:53-68.

Wohlt, J. E. 1989. Use of a silage inoculant to improve feeding stability and intake of a corn silage-grain diet. J. Dairy Sci. 72:545-551.

Woolford, M. K. 1990. The detrimental effects of air on silage. J. Appl. Bacteriol. 68:101-116. 